\title{
Influence of previous surgery on patient-rated outcome after surgery for degenerative disorders of the lumbar spine
}

\author{
Pascal Zehnder ${ }^{1} \cdot$ Emin Aghayev $^{2} \cdot$ Tamas F. Fekete $^{1}$. \\ Daniel Haschtmann $^{1}$ - Tim Pigott ${ }^{3} \cdot$ Anne F. Mannion $^{1}$
}

\begin{abstract}
Purpose Few studies have used multivariate models to quantify the effect of multiple previous spine surgeries on patient-oriented outcome after spine surgery. This study sought to quantify the effect of prior spine surgery on 12-month postoperative outcomes in patients undergoing surgery for different degenerative disorders of the lumbar spine.

Methods The study included 4940 patients with lumbar degenerative disease documented in the Spine Tango Registry of EUROSPINE, the Spine Society of Europe, from 2004 to 2015. Preoperatively and 12 months postoperatively, patients completed the multidimensional Core Outcome Measures Index (COMI; 0-10 scale). Patients' medical history and surgical details were recorded using the Spine Tango Surgery 2006 and 2011 forms. Multiple linear regression models were used to investigate the relationship between the number of previous surgeries and the 12-month postoperative COMI score, controlling for the baseline COMI score and other potential confounders. Results In the adjusted model including all cases, the 12-month COMI score showed a 0.37-point worse value [95\% confidence intervals $(95 \%$ CI $)$ 0.29-0.45;
\end{abstract}

Anne F. Mannion

anne.mannion@yahoo.com

Pascal Zehnder

pascal.zehnder@uzh.ch

1 Spine Center, Schulthess Klinik, Lengghalde 2, 8008 Zurich, Switzerland

2 Institute for Evaluative Research in Medicine, University of Bern, Stauffacherstrasse 78, 3012 Bern, Switzerland

3 Department of Neurosurgery, Walton Centre for Neurology and Neurosurgery, Lower Lane, Liverpool L9 7LJ, UK $p<0.001]$ for each additional prior spine surgery. In the subgroup of patients with lumbar disc herniation, the corresponding effect was 0.52 points $(95 \%$ CI $0.27-0.77$; $p<0.001)$ and in lumbar degenerative spondylolisthesis, 0.40 points (95\% CI $0.17-0.64 ; p=0.001$ ).

Conclusions We were able to demonstrate a clear "doseresponse" effect for previous surgery: the greater the number of prior spine surgeries, the systematically worse the outcome at 12 months' follow-up. The results of this study can be used when considering or consenting a patient for further surgery, to better inform the patient of the likely outcome and to set realistic expectations.

Keywords Previous surgery - Degenerative disorders of the lumbar spine - Patient-rated outcome - Spine Tango * COMI

\section{Introduction}

The literature reports reoperation rates of $10-19 \%[1,2]$ for primary degenerative spinal surgery, varying among different diagnostic subgroups such as lumbar disc herniation [3, 4], degenerative spinal stenosis [5-7], degenerative spondylolisthesis [8] and others [9, 10]. Investigations that set their focus on reoperation rates may lose sight of the main goal of individual treatment, which is typically the relief of pain and improvement in quality of life. The efficacy of different procedures is therefore better assessed in relation to patient-rated well-being [11]. To provide optimal health care a clinician must be able to choose the best treatment for each individual patient, considering individual baseline health parameters and other characteristics. Ideally, clinicians should be able to do this with the support of rigorous prognostic models 
that allow them to predict with reasonable accuracy a patient's expected outcome and likely risks when considering (further) spinal surgery. The development of such models requires investigation of the role of putative risk factors and the size of their effect on patient-rated outcome, in very large groups of representative patients. Such analyses are facilitated by large multicentre patient registries, which are able to provide enough data for powerful regression modelling.

It is well known that the result of repeat surgery is expected to be worse than that of first-time surgery in patients with spinal disorders [12-16]. However, little is known about the specific "dose-response" effect of previous surgery, and no studies have specifically quantified this in relation to validated, multidimensional patient-rated outcome measures.

The goal of the present study was to use data from the EUROSPINE "Spine Tango" registry to quantify the effect of the number of prior surgeries on the score measured using the Core Outcome Measures Index (COMI) [17], 12 months postoperatively, in patients undergoing surgery for degenerative disorders of the lumbar spine. We further sought to quantify the effects in separate subgroups of the most common lumbar degenerative disorders (spinal stenosis without spondylolisthesis, disc herniation, spondylolisthesis, segment disease, and deformity).

\section{Materials and methods}

\section{Patients}

This was a multicentre retrospective analysis of prospectively collected data within the EUROSPINE Spine Tango Registry [18], from 2004 to 2015. Ethics Committee approval was not required to perform the analysis, as it concerned the reuse of routinely collected, anonymised data.

To be included in the present study, the patients had to have a good understanding of written German or English or (after 2006, when other language versions of the questionnaire became available) French, Spanish, Italian or Portuguese, and have both a preoperative and a 12-month follow-up patient-based COMI questionnaire (see below).

Lumbar spine surgery included all cases where, on the Spine Tango Surgery form (see below), the location had been indicated as "lumbar" or "lumbosacral".

Five main degenerative diagnostic groups were created according to detailed inclusion and exclusion criteria (Table 1). These inclusion and exclusion criteria were developed based on the consensus of the Spine Tango Registry Committee consisting of three researchers and three clinicians.

\section{Questionnaires/documentation}

Surgeons systematically documented the details of surgery using the Spine Tango 2006 Surgery Form and (after 2012) the Spine Tango 2011 form. The forms include fields to document the morbidity state [using the American Society of Anaesthesiologists Physical Status Score (ASA; scored 1-5)], extent of lesion (1 segment/vertebral body, 2-3 segments/vertebral bodies, 4-5 segments/vertebral bodies, $>5$ segments/vertebral bodies), previous treatment for main pathology (none, $<3,3-6,6-12$, or $>12$ months of conservative treatment), and the number of previous spine surgeries. The 2011 (but not 2006) form also includes Body Mass Index [BMI $(<20,20-25,26-30,31-35,>35)]$ and smoking status (no, yes). For the authors' own centre, missing BMI and smoking status data from the 2006 forms were extracted retrospectively from the patient records and added to the database. Other cases documented using 2006 forms had to be excluded from the complete-case multivariable analysis, due to the lack of BMI/smoking data.

Preoperatively and at 12 months' follow-up, patients completed the COMI, which is a short, validated, multidimensional outcome instrument, particularly suited for use in registries for monitoring the outcome of spinal surgery from the patient's perspective [17]. The questionnaire contains one question on each of the following: intensity of axial pain (back), intensity of peripheral pain (leg-buttock), back-related function, symptom-specific wellbeing, general quality-of-life, work-disability, and social disability. The COMI is scored from 0 to 10 points (a higher score indicates a worse status), and the Minimal Clinically Important Change (MCIC) score, indicating relevant improvement to the individual patient, has been calculated to be approximately 2-3 points [19-22].

\section{Statistical analysis}

Descriptive data are presented as mean \pm standard deviations (SD) or percentages of the respective patient group. Multiple linear regression was applied to investigate the influence of the number of previous surgeries on the COMI score at 12 months' follow up (FU) whilst controlling for potential confounders such as patient sex, age (continuous variable), morbidity state (ASA-score; ordinal variable, scored 1-4), preoperative COMI score (see above), extent of lesion (as ordinal variable; see above), duration of previous conservative treatment (grouped into "none to $<3$ months" and " $>3$ months"), BMI (as ordinal variable, see above), and smoking status at the time of surgery (see above). Results of the multiple linear regression models are presented as regression coefficients $(B)$ with $95 \%$ confidence intervals $(95 \% \mathrm{CI})$ and the corresponding $p$ values for the number of previous surgeries and each of the other covariates. The 


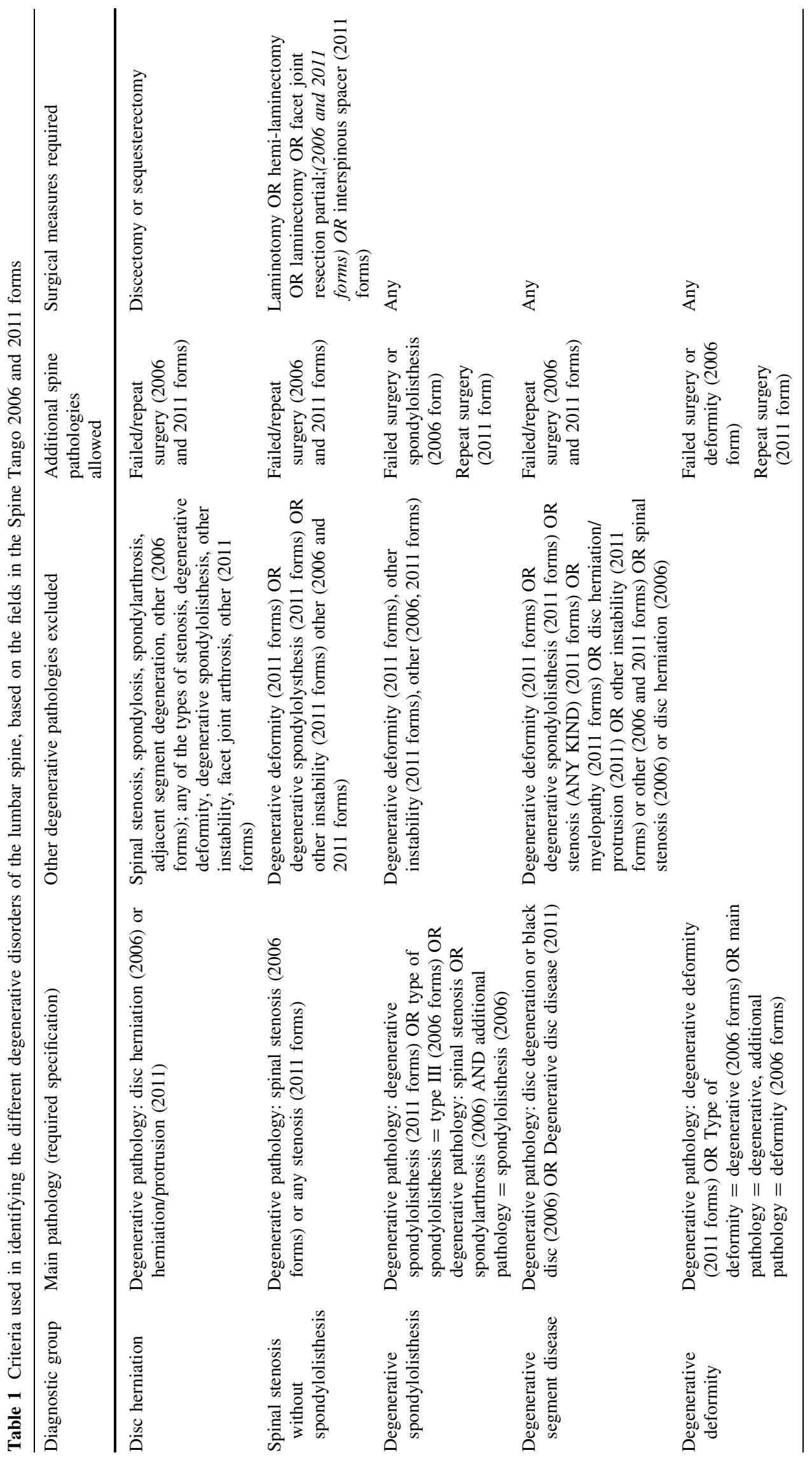


overall model was built including all patients regardless of underlying diagnosis; in sensitivity analyses, subgroup models were calculated for each main diagnosis. All models included the aforementioned variables and all variables were entered simultaneously into the models.

The alpha level for the analyses was set at 0.05. Data were analysed using SPSS version 22 (IBM Corp., USA, 2013).

\section{Results}

\section{Final study group}

Of all the patients in the Spine Tango database, 4940 fulfilled the criteria for inclusion in the model (Fig. 1). Their baseline characteristics are shown in Table 2. In total, 3421 (69.3\%) patients had had no previous surgery; 992 (20.1\%), one; 318 (6.4\%), two; $118(2.4 \%)$, three; $42(0.9 \%)$, four; and 49 $(1.0 \%)$, more than 4 surgeries. Of the 4940 patients, 374 (7.6\%) had lumbar degenerative deformity; $1064(21.5 \%)$, lumbar disc herniation; 828 (16.8\%), lumbar degenerative spondylolisthesis; $232(4.7 \%)$, lumbar degenerative segment disease; and 1442 (29.2\%), lumbar stenosis without spondylolisthesis. $1000(20.2 \%)$ of the patients were not further categorized, as they did not fit the criteria for a distinct diagnosis group (Table 1) (e.g., they had other types or combinations of degenerative pathology or had other pathologies in addition to the degenerative pathology).

\section{Relationship between previous surgery and unadjusted 12-month COMI score}

There was a significant $(p<0.001)$ reduction in the unadjusted COMI score from preoperatively to 12 months' postoperatively for each of the "number of previous surgeries" groups. However, the extent of the reduction diminished as the number of previous surgeries increased (Fig. 2). In other words, the improvement after surgery was less good for those with a greater number of previous surgeries.

\section{Multiple regression model: all lumbar degenerative diseases}

Table 3 shows the results of the overall multiple regression model including all patients. The number of previous surgeries had a significant negative influence on the 12-month COMI score: for each step-increase in the number of previous surgeries, the COMI score at 12 months increased by 0.37 (95\% CI $0.29-0.45$; $p<0.001)$ points. This can be interpreted as showing that the average patient with 3 previous surgeries has a 1.1point higher COMI score 12 months postoperatively compared with a patient operated for the first time.
Fig. 1 Selection of the study group. Note: *including: degenerative spondylolisthesis in 2006 forms, where spondylolisthesis is indicated as main pathology and "degenerative" as predominant etiology; patients with deformity as main pathology and degenerative as additional pathology; and patients with degenerative pathology that could not be categorized into any specific subgroup (Table 1); **where multiple surgery forms were available, only the last dated one was selected for inclusion; ***the Tango 2006 form did not contain the fields BMI and Smoking; 2006-form data were hence only available for the authors' institution, where this information could be added to the database retrospectively; ****if multiple baseline and follow-up COMI forms were available, the one closest to the surgery (maximum 2.5 months before surgery) and the one closest to the 12-month follow-up (maximum 2.5 months before and 3.5 months after the 12-month follow-up date)]were selected as the baseline and 12-month COMI, respectively

Some of the covariates used to adjust the effect of "previous surgery" in the model were also independently associated with the 12-month COMI score (Table 3): a higher preoperative COMI score $(p<0.001)$, greater extent of lesion (number of affected segments) $(p<0.001)$, greater comorbidity $(p<0.001)$, greater BMI $(p<0.001)$, smoking $(p=0.002)$, younger age $(p=0.003)$ and female gender $(p=0.011)$ were associated with higher 12-month COMI scores (i.e., a worse outcome). Previous conservative treatment ( $>$ or $<3$ months) had no significant independent influence on the 12-month COMI scores.

\section{Multiple regression model: lumbar degenerative disease subgroups}

In sensitivity analyses, we evaluated the adjusted effect of the number of previous surgeries in the different diagnostic subgroups (Table 4). The effect of previous surgery on the 12-month COMI score appeared most pronounced in the group with lumbar disc herniation, where, compared with first-time surgery, a single previous surgery resulted in a 0.52-point $(95 \%$ CI $0.27-0.77 ; \quad p<0.001)$ higher ("worse") 12-month COMI score. The corresponding value for lumbar degenerative spondylolisthesis was 0.40 points (95\% CI $0.17-0.64 ; p=0.001)$, and for lumbar spinal stenosis without spondylolisthesis, 0.27 points (95\% CI $0.12-0.42 ; p<0.001)$. For the other lumbar diagnostic subgroups, the $B$ coefficients for the effect of previous surgery failed to achieve statistical significance.

\section{Discussion}

\section{Main findings}

Many studies have shown that repeat spine surgery is associated with worse outcome than first-time surgery, but no previous studies have specifically quantified the effect in relation to patient-rated outcomes. Our adjusted analysis 


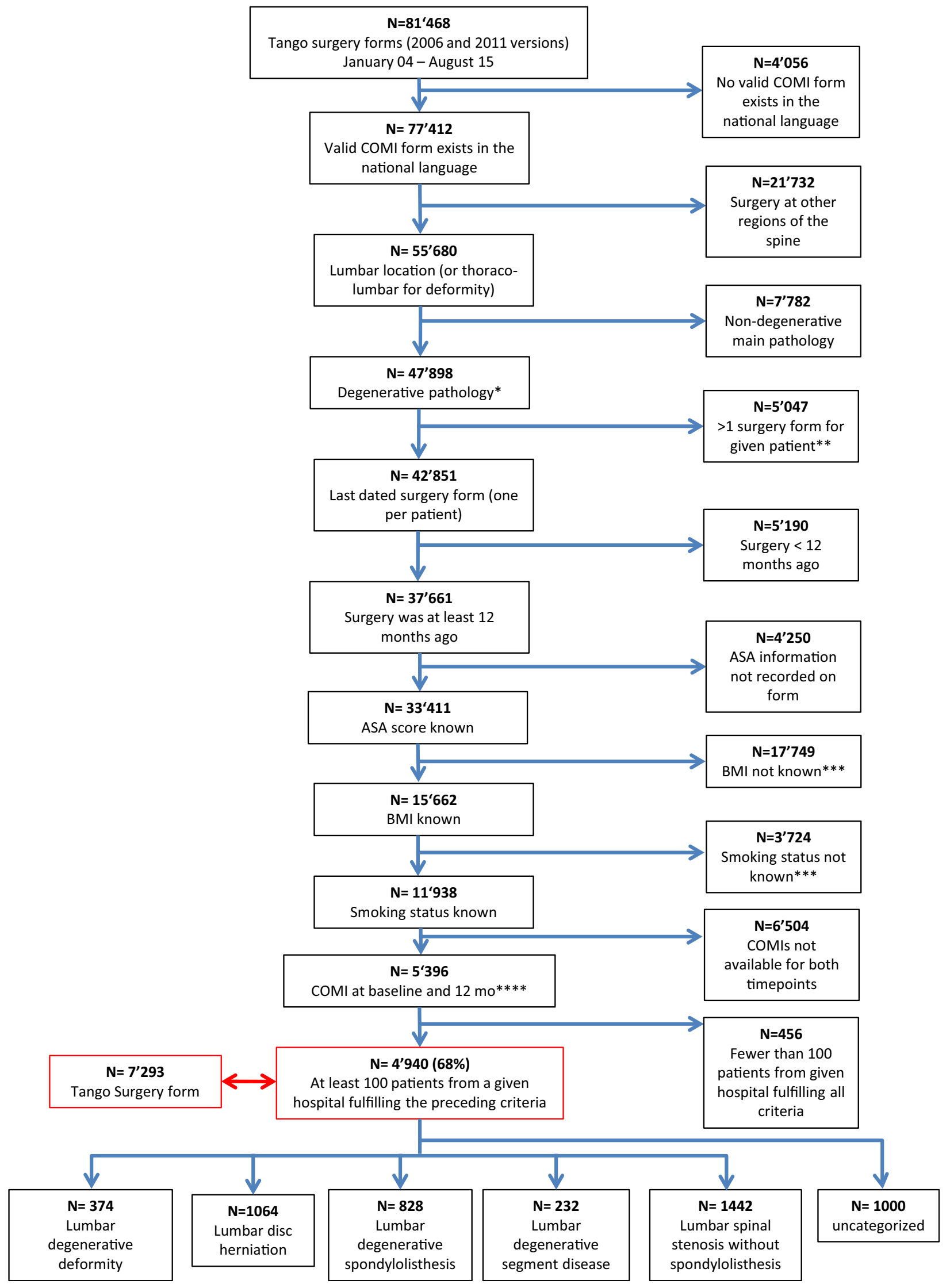


Table 2 Baseline characteristics of the patients

\begin{tabular}{|c|c|}
\hline Number of patients & 4940 \\
\hline Degenerative disorders of the lumbar spine, not further categorized & 1000 \\
\hline Lumbar degenerative deformity & 374 \\
\hline Lumbar disc herniation & 1064 \\
\hline Lumbar degenerative spondylolisthesis & 828 \\
\hline Lumbar degenerative segment disease & 232 \\
\hline Lumbar spinal stenosis without spondylolisthesis & 1442 \\
\hline Age $($ mean $\pm \mathrm{SD})$ & $62 \pm 14.6$ \\
\hline \multicolumn{2}{|l|}{ Sex (\% within patients) } \\
\hline Male & $2307(46.7 \%)$ \\
\hline Female & $2633(53.3 \%)$ \\
\hline COMI score preoperative (mean $\pm \mathrm{SD}$ ) & $7.6 \pm 1.7$ \\
\hline \multicolumn{2}{|l|}{ Number of previous surgeries ( $\%$ of patients) } \\
\hline 0 & $3421(69.3 \%)$ \\
\hline 1 & $992(20.1 \%)$ \\
\hline 2 & $318(6.4 \%)$ \\
\hline 3 & $118(2.4 \%)$ \\
\hline 4 & $42(0.8 \%)$ \\
\hline 5 & $18(0.4 \%)$ \\
\hline$>5$ & $31(0.6 \%)$ \\
\hline \multicolumn{2}{|l|}{ Morbidity state ( $\%$ of patients) } \\
\hline ASA 1 (no disturbance) & $1227(24.8 \%)$ \\
\hline ASA 2 (mild/moderate) & $2707(54.8 \%)$ \\
\hline ASA 3 (severe) & $988(20.0 \%)$ \\
\hline ASA 4 (life threatening) & $18(0.4 \%)$ \\
\hline \multicolumn{2}{|l|}{ Extent of lesion ( $\%$ of patients) } \\
\hline 1 segment/vertebral body & $2479(50.2 \%)$ \\
\hline 2-3 segments/vertebral bodies & $2034(41.2 \%)$ \\
\hline 4-5 segments/vertebral bodies & $349(7.1 \%)$ \\
\hline$>5$ segments/vertebral bodies & $78(1.5 \%)$ \\
\hline \multicolumn{2}{|l|}{ Previous treatment ( $\%$ of patients) } \\
\hline $0-3$ months conservative & $1561(31.6 \%)$ \\
\hline$>3$ months conservative & $3379(68.4 \%)$ \\
\hline \multicolumn{2}{|l|}{ Body mass index ( $\%$ of patients) } \\
\hline$<20$ & $243(4.9 \%)$ \\
\hline $20-25$ & $1749(35.4 \%)$ \\
\hline $26-30$ & $1900(38.5 \%)$ \\
\hline $31-35$ & $783(15.8 \%)$ \\
\hline$>35$ & $265(5.4 \%)$ \\
\hline \multicolumn{2}{|l|}{ Current smoker ( $\%$ of patients) } \\
\hline No & $3913(79.2 \%)$ \\
\hline Yes & $1027(20.8 \%)$ \\
\hline
\end{tabular}

showed that, controlling for baseline COMI scores, patients who have had previous spine surgery have, on average, a 0.4-point higher (i.e., worse) 12-month postoperative COMI score (on the 0-10 scale) for each additional previous spine surgery. Previous studies [19-22] suggest that the minimal clinically important change (MCIC) for individual improvement for the COMI score is $2-3$ points. In relation to this, the size of the stand-alone effect of prior surgery (less improvement in COMI by 0.4 points for each additional surgery), although statistically significant, was not large. However, it may have an important additive effect when combined with other patient characteristics that are associated with worse outcome. In addition to "prior surgery", preoperative COMI score, age, sex, ASA score, extent of lesion, smoking status and BMI were each independently associated with patient outcome at 
12 months postoperative. As such, the combination of a number of unfavourable baseline characteristics would be expected to result in a particularly poor outcome. For example, if looking at two patients starting with the same COMI score of 8 but with different baseline characteristics - the first having an ASA score of 1, a BMI between 20 and 25 , one affected segment, and no previous spinal

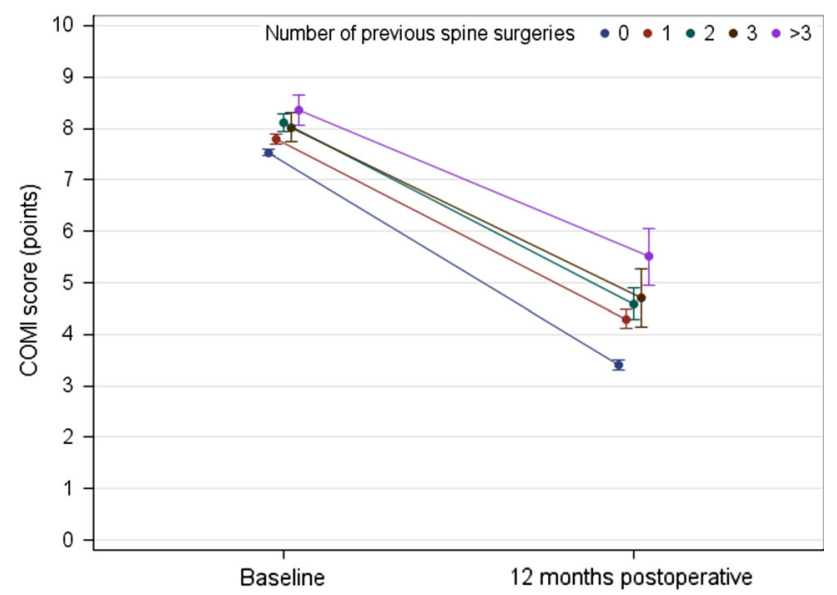

Fig. 2 Influence of number of previous surgeries on baseline (preoperative) and 12-month postoperative COMI scores (unadjusted mean values $\pm 95 \% \mathrm{CI}$ ) surgery; and the second having an ASA score of 2, a BMI between 31 and 35, 2-3 affected segments and 3 previous spine surgeries - the second patient would have an estimated 12-month-postoperative COMI score that is 3 points higher, i.e. notably worse, than the first patient. This means that patients considering spinal surgery and displaying characteristics typical of the second scenario above would have a much smaller chance of achieving the MCIC than would patients depicted by the first scenario. When analysing the diagnostic subgroups in the sensitivity analyses, disc herniation $(p<0.001)$, spinal stenosis without spondylolisthesis $(p<0.001)$ and degenerative spondylolisthesis $(p=0.001)$ all showed a statistically significant contribution of "number of previous surgeries" in explaining the 12-month outcome. Disc herniation showed a regression coefficient of about 0.52 (95 \% CI 0.27-0.77) per additional previous surgery, which is a little higher than that in the overall model. This suggests that in patients with lumbar disc herniation the 12-month outcome is influenced to a greater extent by prior surgery, when compared with an average patient with lumbar degenerative pathology. No effect was seen in patients with degenerative deformity or degenerative segment disease. Possibly with deformity surgery, many of the prior operations had been part of a planned series of interventions rather than "revisions" per

Table 3 Multiple regression model for all patients with degenerative disorders of the lumbar spine

\begin{tabular}{|c|c|c|c|c|c|c|c|c|c|}
\hline \multirow[t]{2}{*}{ Model } & \multicolumn{2}{|c|}{ Unstandardized coefficients } & \multirow{2}{*}{$\begin{array}{l}\text { Standardized } \\
\text { coefficients } \\
\beta\end{array}$} & \multirow[t]{2}{*}{$p$ value } & \multicolumn{2}{|c|}{$95 \% \mathrm{CI}$ for $B$} & \multicolumn{3}{|l|}{ Correlations } \\
\hline & $B$ & SE & & & Lower & Upper & Zero-order & Partial & Part \\
\hline Constant & -1.62 & 0.28 & - & $<0.001$ & -2.17 & -1.08 & - & - & - \\
\hline Number of previous spine surgeries & 0.37 & 0.04 & 0.12 & $<0.001$ & 0.29 & 0.45 & 0.17 & 0.13 & 0.12 \\
\hline Preoperative COMI score & 0.37 & 0.02 & 0.22 & $<0.001$ & 0.33 & 0.41 & 0.26 & 0.23 & 0.22 \\
\hline Extent of lesion & 0.21 & 0.06 & 0.05 & $<0.001$ & 0.09 & 0.32 & 0.09 & 0.05 & 0.05 \\
\hline Morbidity state & 0.50 & 0.07 & 0.12 & $<0.001$ & 0.36 & 0.64 & 0.17 & 0.10 & 0.09 \\
\hline BMI & 0.29 & 0.04 & 0.10 & $<0.001$ & 0.21 & 0.37 & 0.13 & 0.10 & 0.09 \\
\hline Current smoker & 0.29 & 0.10 & 0.04 & 0.002 & 0.11 & 0.48 & 0.06 & 0.04 & 0.04 \\
\hline Age & -0.01 & 0.00 & -0.05 & 0.003 & -0.02 & 0.00 & 0.03 & -0.04 & -0.04 \\
\hline Sex & -0.20 & 0.08 & -0.03 & 0.011 & -0.35 & -0.04 & -0.06 & -0.04 & -0.03 \\
\hline Previous conservative treatment & 0.00 & 0.08 & 0.00 & 0.962 & -0.16 & 0.17 & -0.03 & 0.00 & 0.00 \\
\hline
\end{tabular}

Table 4 Regression coefficients for the variable "number of previous surgeries" from the multiple regression analyses of the diagnostic subgroups

\begin{tabular}{lrrrr}
\hline & \multicolumn{1}{c}{$N$} & \multicolumn{1}{c}{$B$} & \multicolumn{1}{c}{$95 \%$ CI } & $p$ value \\
\hline All lumbar degenerative groups (as per Table 2) & 4940 & 0.37 & 0.29 to 0.45 & $<0.001$ \\
Lumbar degenerative deformity & 374 & 0.19 & -0.04 to 0.42 & 0.105 \\
Lumbar disc herniation & 1064 & 0.52 & 0.27 to 0.77 & $<0.001$ \\
Lumbar degenerative spondylolisthesis & 828 & 0.40 & 0.17 to 0.64 & 0.001 \\
Lumbar degenerative segment disease & 232 & 0.12 & -0.26 to 0.49 & 0.529 \\
Lumbar spinal stenosis without spondylolisthesis & 1442 & 0.27 & 0.12 to 0.42 & $<0.001$ \\
\hline
\end{tabular}

$N$, number of patients; $B$, unstandardized regression coefficient 
se; for degenerative segment disease, we have no clear explanation for the lack of influence of prior surgery on outcome, although the smaller group size may perhaps have limited the power to detect any such effect.

Possible explanations for the less good response to surgery when a patient has undergone prior surgery include the difficulty in accurately identifying the pain source/generator, i.e. incorrect diagnosis; the more difficult and/or longer surgery required for revision; repeated tissue/muscle damage and/or scar tissue formation associated with previous interventions that may cause ongoing pain/ disability; socioeconomic or psychological problems that ensue after previously unsuccessful surgery; and long-term consumption of painkillers (especially opioids). In the present study, it was not possible to identify the underlying nature of the association, in terms of mediating factors; the purpose of the study was not, however, to address causality, but rather prediction.

As mentioned earlier, a higher preoperative COMI score was associated with a higher COMI score 12 months after the operation. This means that patients starting with worse preoperative pain, disability and quality of life cannot expect to reach the same absolute 12-month COMI score compared with patients starting off with a better preoperative status. Our predictive model also showed that the number of affected segments was a significant factor influencing patient outcome. When multiple segments or vertebral bodies were involved, the outcome was significantly worse. In the present study, we also found a correlation between the ASA score and the 12-month COMI score. This was expected and corroborates previous findings [23]. Operating on patients with a higher ASA score (i.e. poorer general health) usually means that the surgery will be more challenging and more likely to result in perioperative complications. Furthermore, it may take longer and more effort for a patient to recover after spine surgery if they have various systemic conditions influencing function and quality of life [23]. Another significant covariate was body mass index, confirming the findings of several previous studies [24-26]. Loading of the lumbar spine increases substantially with greater BMI [27], and excessive weight could have a negative influence on the weakened/degenerate spine, effecting a worse outcome. A further lifestyle-associated covariate that showed a significant influence on patient outcome was smoking, with smokers showing a 0.29-point (95\% CI 0.11-0.48; $p<0.05$ ) worse COMI score 12 months postoperatively than non-smokers. This finding supports the results of previous studies [28]. Our model also suggested that, all else being equal, older patients had a slightly but significantly lower ("better") 12-month COMI score $(B=-0.01)$ than younger patients. A 10 -year age difference would result in a 0.10 -point lower COMI score
12 months postoperatively. The influence of age on the outcome of spine surgery is a controversial matter. It is generally known that elderly patients have more perioperative complications than younger patients $[29,30]$, but the limited literature on age-related patient-rated outcome in spine surgery tends to suggest that age does not have any significant influence [31]. Our final significant covariate was sex, with male patients showing a slightly lower (better) 12-month COMI score than female patients $(B=-0.20)$.

\section{Strength and weaknesses of the study}

Our study has various strengths and weaknesses. One of its strengths is clearly the large sample size, which allowed us to investigate subgroups of five different diagnoses. The data come from an international registry, making them more representative than data from a single institution. Surgical details were documented in a standardized fashion, using the EUROSPINE Spine Tango surgery form. In our multiple regression models we included all potentially relevant observed confounders, to unmask the independent influence of our variable of interest, "number of previous surgeries". Nonetheless, there might have been other unmeasured confounders that had an effect on the 12-month COMI score. The COMI does not include any questions of a psychological nature, such as fear-avoidance, catastrophising, anxiety or depression, which represent possible predictors of patientrated outcome and may be considered for inclusion in future versions of the COMI [32, 33]. However, whilst these might be expected to have explained more of the variance in the model, they would not necessarily be expected to diminish the unique role of previous surgery, unless they were very highly associated with and also had a greater effect than previous surgery.

Another weakness of the study is that the introduction of the "2011 Spine Tango form" in 2012 resulted in additional variables being included that were not present in the "2006" form, notably BMI and smoking status data. This data was retrieved from the medical files of the patients from the authors' own centre, but could not be retrieved for the anonymised data sets in the registry (and hence led to a reduction in the total sample size).

Further, we are aware of the fact that the statistical significance reported for many of the findings resulted from the very large sample size and does not necessarily translate to clinical significance. In relation to this, we have attempted to indicate the scale of the effects and their likely impact by highlighting the size of the relevant regression coefficients. The small size of some of the diagnostic groups may have rendered the subgroup analyses underpowered. These should be investigated further, as the 
registry accumulates more data. And finally, we were not able to ascertain the reason why a second or third operation was carried out, i.e., whether it was due to a failed previous surgery or recurrence/progression of an ongoing degenerative problem, whether it was for the same diagnosis, or whether the previous surgery was even at the same vertebral level. Interestingly, previous studies using multivariate regression analyses have shown that prior surgery at the same level and prior surgery at other lumbar levels are both significant independent predictors of poor outcome after surgery for 1 and 2-level spinal stenosis [34]. Although a lack of knowledge regarding the nature of prior surgeries is a limitation of registry data, the "number of previous surgeries" is nonetheless a parameter that reveals a notable association with outcome, is known when contemplating further surgery, and may hence be of use in future multidimensional predictive models.

\section{Summary}

In patients with degenerative disorders of the lumbar spine, an increasing number of previous surgeries was significantly associated with a less good outcome 12 months postoperatively. This suggests that patients with a history of prior spinal surgery should be critically evaluated before undergoing further spinal surgical measures, since the outcome tends to be less good than that for first-time procedures. Especially when coupled with other predictors of a poor outcome, the benefits of surgery should be carefully weighed up against the risks. Using the multiple regression equations reported here-perhaps extended with additional predictors and supported by tighter confidence intervals as the Spine Tango database grows-the clinician should be in a better position to estimate more precisely the likely effect of surgery on patient-rated outcome and inform the patient accordingly; it is well known that more realistic expectations of surgery are associated with better outcomes [35, 36].

Acknowledgments The study was funded by the Schulthess Klinik Research funds, the Mäxi Foundation (Switzerland), and Eurospine's Spine Tango. We are grateful to Malgorzata Roos, Dept Biostatistics, University of Zürich, for her advice and assistance in conducting the statistical analysis. The participants of the Spine Tango Registry are acknowledged for their contribution of data. The data of the following centers were used in the present study (in alphabetic order of country, city, hospital and department): Dept. Orthopedic Surgery, Saint Pierre Clinic, Ottignies (Belgium); Dept. of Orthopaedic Surgery, University Hospital, St. Luc (Belgium); Dept. of Neurosurgery, Bethesda Hospital, Basel (Switzerland); Dept. of Orthopedic Surgery, Salem Hospital, Bern (Switzerland); Spine Center, Schulthess Clinic, Zurich (Switzerland); Dept. of Neurosurgery, The Walton Centre, Liverpool (UK).

\section{Compliance with ethical standards}

Conflict of interest None.

\section{References}

1. Martin BI, Mirza SK, Comstock BA, Gray DT, Kreuter W, Deyo RA (2007) Reoperation rates following lumbar spine surgery and the influence of spinal fusion procedures. Spine (Phila $\mathrm{Pa} 1976$ ) 32:382-387. doi:10.1097/01.brs.0000254104.55716.46

2. Hu RW, Jaglal S, Axcell T, Anderson G (1997) A populationbased study of reoperations after back surgery. Spine (Phila Pa 1976) 22:2265-2270 (discussion 2271)

3. Fritzell P, Knutsson B, Sanden B, Stromqvist B, Hagg O (2014) Recurrent versus primary lumbar disc herniation surgery: patientreported outcomes in the Swedish Spine Register Swespine. Clin Orthop Relat Res. doi:10.1007/s11999-014-3596-8

4. Kim CH, Chung CK, Park CS, Choi B, Kim MJ, Park BJ (2013) Reoperation rate after surgery for lumbar herniated intervertebral disc disease: nationwide cohort study. Spine (Phila Pa 1976) 38:581-590. doi:10.1097/BRS.0b013e318274f9a7

5. Katz JN, Lipson SJ, Chang LC, Levine SA, Fossel AH, Liang MH (1996) Seven- to 10-year outcome of decompressive surgery for degenerative lumbar spinal stenosis. Spine (Phila Pa 1976) 21:92-98

6. Herno A, Airaksinen O, Saari T, Sihvonen T (1995) Surgical results of lumbar spinal stenosis. A comparison of patients with or without previous back surgery. Spine (Phila Pa 1976) 20:964-969

7. Lad SP, Babu R, Ugiliweneza B, Patil CG, Boakye M (2014) Surgery for spinal stenosis: long-term reoperation rates, health care cost, and impact of instrumentation. Spine (Phila Pa 1976) 39:978-987. doi:10.1097/BRS.0000000000000314

8. Nork SE, Hu SS, Workman KL, Glazer PA, Bradford DS (1999) Patient outcomes after decompression and instrumented posterior spinal fusion for degenerative spondylolisthesis. Spine (Phila Pa 1976) 24:561-569

9. Malter AD, McNeney B, Loeser JD, Deyo RA (1998) 5-year reoperation rates after different types of lumbar spine surgery. Spine (Phila Pa 1976) 23:814-820

10. Osterman H, Sund R, Seitsalo S, Keskimaki I (2003) Risk of multiple reoperations after lumbar discectomy: a populationbased study. Spine (Phila Pa 1976) 28:621-627. doi:10.1097/01. BRS.0000049908.15854.ED

11. Deyo RA, Battie M, Beurskens AJ, Bombardier C, Croft P, Koes B, Malmivaara A, Roland M, Von Korff M, Waddell G (1998) Outcome measures for low back pain research. A proposal for standardized use. Spine (Phila Pa 1976) 23:2003-2013

12. Waddell G, Kummel EG, Lotto WN, Graham JD, Hall H, McCulloch JA (1979) Failed lumbar disc surgery and repeat surgery following industrial injuries. J Bone Joint Surg Am 61:201-207

13. Vik A, Zwart JA, Hulleberg G, Nygaard OP (2001) Eight year outcome after surgery for lumbar disc herniation: a comparison of reoperated and not reoperated patients. Acta Neurochir (Wien) 143:607-610 (discussion 610-611)

14. Dai LY, Zhou Q, Yao WF, Shen L (2005) Recurrent lumbar disc herniation after discectomy: outcome of repeat discectomy. Surg Neurol 64:226-231. doi:10.1016/j.surneu.2004.11.003 (discussion 231)

15. Skaf G, Bouclaous C, Alaraj A, Chamoun R (2005) Clinical outcome of surgical treatment of failed back surgery syndrome. Surg Neurol 64:483-488. doi:10.1016/j.surneu.2005.04.009 (discussion 488-489)

16. Sobottke R, Herren C, Siewe J, Mannion AF, Roder C, Aghayev E (2015) Predictors of improvement in quality of life and pain relief in lumbar spinal stenosis relative to patient age: a study based on the Spine Tango registry. Eur Spine J. doi:10.1007/ s00586-015-4078-8 
17. Mannion AF, Porchet F, Kleinstuck FS, Lattig F, Jeszenszky D, Bartanusz V, Dvorak J, Grob D (2009) The quality of spine surgery from the patient's perspective. Part 1: The Core Outcome Measures Index in clinical practice. Eur Spine J 18(Suppl 3):367-373. doi:10.1007/s00586-009-0942-8

18. Röder C (2015) EUROSPINE Spine Tango. EUROSPINE. http:// www.eurospine.org/spine-tango.htm. Accessed 02.07.2015

19. Mannion AF, Porchet F, Kleinstuck FS, Lattig F, Jeszenszky D, Bartanusz V, Dvorak J, Grob D (2009) The quality of spine surgery from the patient's perspective: Part 2. Minimal clinically important difference for improvement and deterioration as measured with the Core Outcome Measures Index. Eur Spine J 18(Suppl 3):374-379. doi:10.1007/s00586-009-0931-y

20. Monticone M, Ferrante S, Maggioni S, Grenat G, Checchia GA, Testa M, Teli MG, Mannion AF (2014) Reliability, validity and responsiveness of the cross-culturally adapted Italian version of the Core Outcome Measures Index (COMI) for the neck. Eur Spine J 23:863-872. doi:10.1007/s00586-013-3092-y

21. Fankhauser CD, Mutter U, Aghayev E, Mannion AF (2012) Validity and responsiveness of the Core Outcome Measures Index (COMI) for the neck. Eur Spine J 21:101-114. doi:10. 1007/s00586-011-1921-4

22. Genevay S, Marty M, Courvoisier DS, Foltz V, Mahieu G, Demoulin C, Fontana AG, Norberg M, de Goumoens P, Cedraschi C, Rozenberg S, Section Rachisde la Societe Francaise de Rhumatologie (2014) Validity of the French version of the Core Outcome Measures Index for low back pain patients: a prospective cohort study. Eur Spine J 23:2097-2104. doi:10.1007/ s00586-014-3325-8

23. Mannion AF, Fekete TF, Porchet F, Haschtmann D, Jeszenszky D, Kleinstuck FS (2014) The influence of comorbidity on the risks and benefits of spine surgery for degenerative lumbar disorders. Eur Spine J 23(Suppl 1):S66-S71. doi:10.1007/s00586014-3189-y

24. Seicean A, Alan N, Seicean S, Worwag M, Neuhauser D, Benzel EC, Weil RJ (2014) Impact of increased body mass index on outcomes of elective spinal surgery. Spine (Phila Pa 1976) 39:1520-1530. doi:10.1097/brs.0000000000000435

25. Auffinger B, Lam S, Kraninger J, Shen J, Roitberg BZ (2014) The impact of obesity on surgeon ratings and patient-reported outcome measures after degenerative cervical spine disease surgery. World Neurosurg 82:e345-e352. doi:10.1016/j.wneu.2013.09. 053

26. Knutsson B, Michaelsson K, Sanden B (2013) Obesity is associated with inferior results after surgery for lumbar spinal stenosis: a study of 2633 patients from the Swedish Spine Register. Spine (Phila Pa 1976) 38:435-441. doi:10.1097/BRS. 0b013e318270b243
27. Hajihosseinali M, Arjmand N, Shirazi-Adl A (2015) Effect of body weight on spinal loads in various activities: a personalized biomechanical modeling approach. J Biomech 48:276-282. doi:10.1016/j.jbiomech.2014.11.033

28. Gulati S, Nordseth T, Nerland US, Gulati M, Weber C, Giannadakis C, Nygaard OP, Solberg TK, Solheim O, Jakola AS (2015) Does daily tobacco smoking affect outcomes after microdecompression for degenerative central lumbar spinal stenosis? A multicenter observational registry-based study. Acta Neurochir (Wien) 157:1157-1164. doi:10.1007/s00701-015-2437-1

29. Severn A (2007) Anaesthesia and the preparation and management of elderly patients undergoing surgery. Eur $\mathrm{J}$ Cancer 43:2231-2234. doi:10.1016/j.ejca.2007.08.013

30. Sobottke R, Aghayev E, Roder C, Eysel P, Delank SK, Zweig T (2012) Predictors of surgical, general and follow-up complications in lumbar spinal stenosis relative to patient age as emerged from the Spine Tango Registry. Eur Spine J 21:411-417. doi:10. 1007/s00586-011-2016-y

31. Ulrich NH, Kleinstuck F, Woernle CM, Antoniadis A, Winklhofer S, Burgstaller JM, Farshad M, Oberle J, Porchet F, Min K (2015) Clinical outcome in lumbar decompression surgery for spinal canal stenosis in the aged population: a prospective Swiss multicenter cohort study. Spine (Phila Pa 1976) 40:415-422. doi:10.1097/brs.0000000000000765

32. Adogwa O, Parker SL, Shau DN, Mendenhall SK, Aaronson OS, Cheng JS, Devin CJ, McGirt MJ (2012) Preoperative Zung Depression Scale predicts outcome after revision lumbar surgery for adjacent segment disease, recurrent stenosis, and pseudarthrosis. Spine J 12:179-185. doi:10.1016/j.spinee.2011.08.014

33. Cedraschi C, Marty M, Courvoisier DS, Foltz V, Mahieu G, Demoulin C, Gierasimowicz Fontana A, Norberg M, de Goumoens P, Rozenberg S, Genevay S (2015) Core Outcome Measure Index for low back patients: do we miss anxiety and depression? Eur Spine J. doi:10.1007/s00586-015-3935-9

34. Nerland US, Jakola AS, Giannadakis C, Solheim O, Weber C, Nygaard OP, Solberg TK, Gulati S (2015) The risk of getting worse: predictors of deterioration after decompressive surgery for lumbar spinal stenosis - a multicenter observational study. World Neurosurg. doi:10.1016/j.wneu.2015.05.055

35. Soroceanu A, Ching A, Abdu W, McGuire K (2012) Relationship between preoperative expectations, satisfaction, and functional outcomes in patients undergoing lumbar and cervical spine surgery: a multicenter study. Spine (Phila Pa 1976) 37:E103-E108. doi:10.1097/BRS.0b013e3182245c1f

36. Mannion AF, Junge A, Elfering A, Dvorak J, Porchet F, Grob D (2009) Great expectations: really the novel predictor of outcome after spinal surgery? Spine (Phila Pa 1976) 34:1590-1599. doi:10.1097/BRS.0b013e31819fcd52 